\title{
Three dimentional CT-based evaluation of the supraclavicular and infraclavicular nodes and calculation of the administrated dose
}

\author{
Mohamed A Aboziada ${ }^{1 *}$, Mostafa A Hashem² and Ahmed S Ahmed ${ }^{2}$ \\ *Correspondence: maboziada70@yahoo.com \\ 'Department of radiation Oncology, South Egypt Cancer Institute, University of Assiut, Egypt. \\ ${ }^{2}$ Department of medical physics, South Egypt Cancer Institute, University of Assiut, Egypt.
}

\begin{abstract}
Background: Comprehensive radiation therapy fields used in the management of early-stage breast cancer. Our aim to determine the variability of the depth of supraclavicular (SCV) \& infraclavicular (ICV) nodes, to estimate the actual radiation dose received by these regions in a series of patients treated in the traditional technique, and to compare these doses with those received by using an optimized dosimetric technique.

Methods: In 20 patients undergoing treatment-planning computed tomography (CT) scanning in the treatment position, the maximum depth of the SCV and ICV lymph nodes and brachial plexus were measured on CT images. Doses received at the $90 \%$ isodose surface for the SCV and ICV volumes were then estimated by using traditional dose calculations and optimized planning. A repeated measures analysis of covariance was used to compare the SCV and ICV depths and to compare the doses achieved with the traditional and optimized methods.

Results: We found that SCV nodes $>3 \mathrm{~cm}$ and ICV nodes $>4.5 \mathrm{~cm}$ will not be covered by $90 \%$ isodose surface. However, as the depth to the SCV and ICV nodes increases, the percentage of the SCV volume encompassed within the $90 \%$ isodose surface significantly decreases for cases of therapy planned by using traditional planning versus the conformal optimized plan $(\mathrm{p}<0.05 \%)$.

Conclusion: Conformal optimized planning provided improved dosimetric coverage compared with traditional techniques.
\end{abstract}

Keywords: Breast, conformal radiotherapy, supraclavicular irradiation

\section{Introduction}

The benefit of post-operative loco-regional therapy in the management of high risk early-stage breast cancer has been demonstrated. Recent randomized trials by Overgaard and Ragaz; and meta-analysis by Whelan have shown a significant benefit in survival by the addition of post mastectomy radiation therapy in patients with positive axillary nodes [1-4]. Comprehensive radiation therapy fields used in these trials have included not only the chest wall but also the regional lymph nodes. Although the exact contribution of regional treatment to the survival benefit is uncertain, it is clear from these studies that treatment to regional sites is of therapeutic benefit.

Management of the axilla in the treatment of breast cancer is primarily surgical, with level I, II dissection. Axillary recurrence is approximately $1 \%-2 \%$ following surgical dissection $[5,6]$. However, increasing the number of involved axillary nodes in level I, II dissection, the risk of involvement of level III ( Infra-clavicular; ICV region) and the supra-clavicular (SCV) nodes increases as well $[7,8]$. Radiation therapy is used to treat patients at high risk for microscopic residual disease of these nodes, resulting in rates of regional first failure of only about 1.5\% [9].

Usually, the SCV nodes and the ICV have been treated with radiotherapy by using a standard single anterior field, with full dose prescribed to a point in the central axis 3 $\mathrm{cm}$ deep to the surface of the skin. This technique was developed in the pre-CT era. Although the nodes in these regions considered at risk, tissues not at risk like shoulder musculature are also included. This increases the potential for radiation-associated complications [10]. Uniform dosing to a depth of $3 \mathrm{~cm}$ in all patients for an arbitrarily defined nodal volume is also of concern, whereas a large variation in position of the regional LNs between patients has been established [11-14]. This depends on body size, weights, arm position and depth of subcutaneous adipose tissue among individuals. Computed tomographic (CT) simulation allows precise localization of the entire nodal regions at risk and to deliver full-dose radiation therapy optimized to these targets. It is also important to estimate the actual dose received by organs at risk, such as the brachial plexus and spinal cord.

We carried out a prospective study to delineate the SCV and ICV on CT scans, to define the course of the brachial

(C) 2013 Aboziada et al; licensee Herbert Publications Ltd. This is an Open Access article distributed under the terms of Creative Commons Attribution License (http://creativecommons.org/licenses/by/3.0). This permits unrestricted use, distribution, and reproduction in any medium, provided the original work is properly cited. 
Aboziada et al. Journal of Cancer Therapeutics \& Research 2013,

http://www.hoajonline.com/journals/pdf/2049-7962-2-11.pdf

doi: $10.7243 / 2049-7962-2-11$

Table 1. Regional Nodal Contours: Anatomical Boundaries according to RTOG.

\begin{tabular}{|c|c|c|c|c|c|c|}
\hline & Cranial & Caudal & Anterior & Posterior & Lateral & Medial \\
\hline SCV & $\begin{array}{l}\text { Caudal to the cricoid } \\
\text { cartilage }\end{array}$ & $\begin{array}{l}\text { Junction of brachio- } \\
\text { ceph.- axillary viens./ } \\
\text { caudal edge of clavicle } \\
\text { head }\end{array}$ & $\begin{array}{l}\text { Sternocleido-mastoid } \\
\text { (SCM) muscle (m.) }\end{array}$ & $\begin{array}{l}\text { Anterior aspect of } \\
\text { the scalene } \mathrm{m} \text {. }\end{array}$ & $\begin{array}{l}\text { Cranial: lateral edge of } \\
\text { SCM m. Caudal: junction } \\
\text { 1st rib-clavicle }\end{array}$ & $\begin{array}{l}\text { Excludes thyroid } \\
\text { and trachea }\end{array}$ \\
\hline ICV & $\begin{array}{l}\text { Pec. Minor } \mathrm{m} \text {. insert } \\
\text { on cricoid }\end{array}$ & $\begin{array}{l}\text { Axillary vessels cross } \\
\text { medial edge of Pec. } \\
\text { Minor m. }\end{array}$ & $\begin{array}{l}\text { Posterior surface Pec. } \\
\text { Major m. }\end{array}$ & $\begin{array}{l}\text { Ribs and intercostal } \\
\text { muscles }\end{array}$ & $\begin{array}{l}\text { Medial border of Pec. } \\
\text { Minor } \mathrm{m} \text {. }\end{array}$ & Thoracic inlet \\
\hline
\end{tabular}

SCV: supraclavicular fossa; ICV: infraclavicular fossa.

plexus and spinal cord, to determine the variability of depth of the nodes, to calculate the actual radiation dose received by these nodal regions in patients treated in the traditional technique, and to compare these doses with those received with an optimized dosimetric technique.

\section{Patients and methods}

Contrast material-enhanced CT scans obtained in 20 patients consecutively treated with radiation therapy at the department of radiotherapy, were used to delineate the anatomy of the SCV fossa and ICV. Each patient had been diagnosed with stage II breast cancer with pathologically positive axillary nodes and had undergone surgery either modified radical mastectomy (MRM) or conservative breast surgery. Radiation therapy is used to treat patients at high risk for microscopic disease of these nodes (SCV\& ICV). Dose of radiation was $50 \mathrm{~Gy} / 25$ fractions/ 5 weeks. CT was then performed in the treatment position. Patient was supine in breast holder with head rest, ipsilateral arm above the head and face turned to opposite side. Patient CT sections were contiguously obtained at $5-\mathrm{mm}$ intervals from the mid-neck to the diaphragm with administration of nonionic intravenous contrast material. CT images transferred to the planning system. The SCV and ICV nodes, brachial plexus and spinal cord were carefully outlined on each transverse $C T$ section by using the three-dimensional system (Table 1). Summarized the boundaries of both SCV and ICV nodes according to Radiotherapy Oncology Group (RTOG) guidelines [15].

The course of the brachial plexus was also outlined on each $C T$ section. The brachial plexus usually arises from the roots of the fifth cervical (C5) through the first thoracic (T1) nerves. At approximately the $\mathrm{T} 1$ vertebral level, the brachial plexus courses between the anterior and middle scalene muscles. In the inferior portion of the SCV, the brachial plexus closely follows the path of the subclavian artery. Specifically, the neural bundles are located just anterior to the subclavian artery, and then course immediately posterior and parallel to the subclavian artery. The terminal branches of the plexus then surround the subclavian-axillary artery. Thus, even though the brachial plexus can be difficult to identify on transverse $\mathrm{CT}$ images, the anterior and middle scalene muscles and subclavian-axillary arteries can be used to identify the expected course of the plexus [16].
Radiation therapy doses to the SCV and ICV regions were estimated by using both a traditional and an optimized technique. For the traditional method, a single anterior field was set at $100 \mathrm{~cm}$ source-to-skin distance. This field has generally extended superiorly to the thyro-cricoid membrane, inferiorly to the inferior aspect of the clavicular head, medially to the midline, and laterally abutting the humeral head. The gantry was angled 10 degrees away from the spinal cord. The dose to the supr-clavicular field was calculated to the center of the field at a depth of 3 $\mathrm{cm}$. Doses received at the $90 \%$ isodose surface for the SCV and ICV volumes were then calculated by using the Xio planning system. In identifying these structures, we have superimposed the dose calculations traditionally delivered to these regions and have estimated the doses actually received by these nodal groups. For optimized technique, the depth of normalization was determined such that the $90 \%$ isodose surface covered the SCV and $\mathrm{ICV}$ volumes. Posterior axillary boost (small field) was used in some cases in optimized plan. Six-megavolt photons and lung inhomogeneity corrections were used for both calculation techniques. The depth to the deepest aspect of the target volume was measured with the gantry angle set at 0 degree in all patients.

Brachial plexus nerves have an irregular course and the patient body habitus varied, therefore, the distance from the skin to the plexus varied according the position. The minimum ( $\mathrm{min}$ ) and maximum ( $\mathrm{max}$ ) depths from the skin to the brachial plexus nerves were measured on each scan. The mean brachial plexus (BP) depth, calculated as (BP min $+\mathrm{BP} \max ) / 2$. The maximum dose to the spinal cord was also estimated. The cervical oesophagus and the apex of ipsilateral lung were contoured and the mean dose for each case was estimated then the median dose for all patients in both group.

The statistical method is a paired-comparison t- test in that it is used to estimate the within-patient correlation between plans.

\section{Results}

Patient's age ranged from 40 to 65 years (median, 52 years). Fourteen patients had MRM and 6 patients had intact breast. The median weight of patients was 71 kilograms (range, 52 to 90). There is a direct proportion between 


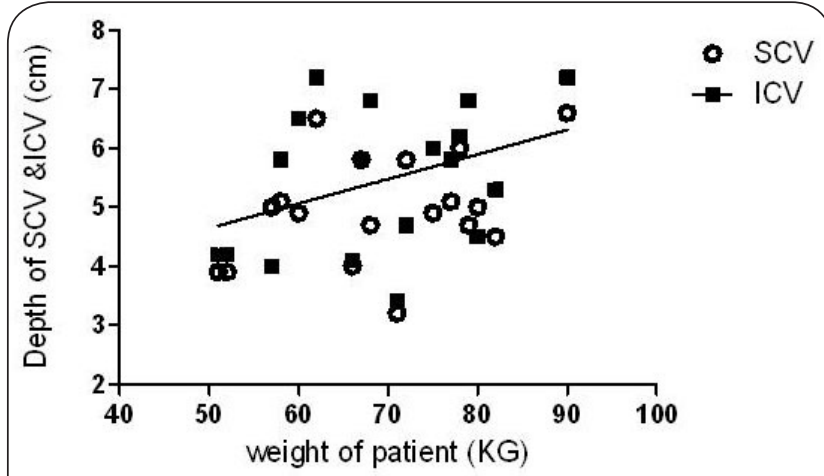

Figure 1. Relation between weight of patients and depth of LNs.

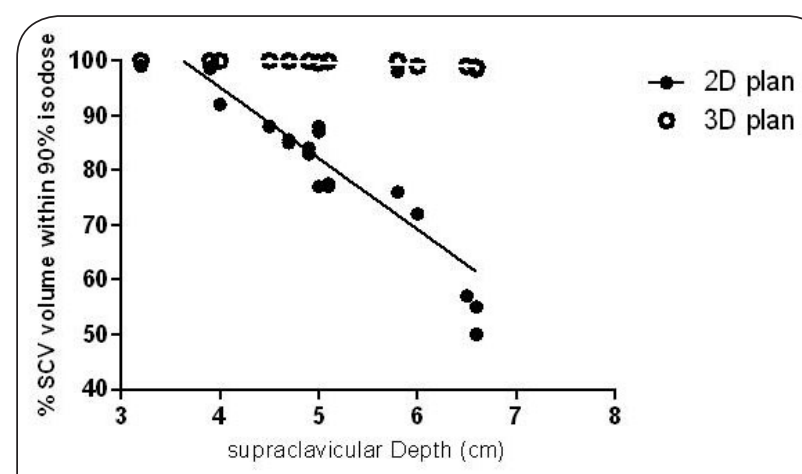

Figure 2. showed the relation between depth of the SCV and the percentage of the SCV volume encompassed within the $90 \%$ isodose surface for $2 \mathrm{D} \& 3 \mathrm{D}$.

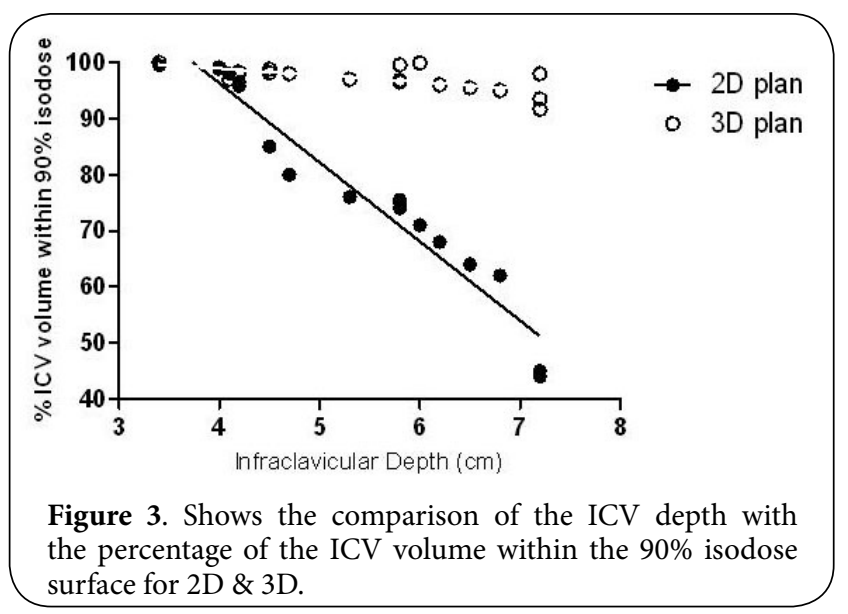

the weight of patient and the depth of LN (Figure 1). The field size encompassed the SCV and ICV is very tight in the optimized 3D plan rather than the traditional 2D plan. The median field size is $10.8 \times 7.85 \mathrm{~cm}$ and $8.2 \times 5.8 \mathrm{~cm}$ for the traditional and optimized plans respectively. The SCV field of the optimized 3D plan restricted the radiation dose to the defined nodal volumes with sparing tissues at the lateral and superior aspects of a traditional SCV field. For the conformal optimized plans, the gantry angle was modified in all patients to cover both SCV and ICV volumes. The gantry angle was $15^{\circ}$ in 6 patients, 200 in 6 patients, 220 in 4 patients, and 250 in 4 patients.

The maximum median depth of SCV nodes was $5 \mathrm{~cm}$ (range, 3.2-6.6 cm). In the 3D conformal plan, $99.5 \%$ of the $\mathrm{SCV}$ volume was covered by the $90 \%$ isodose surface. This compares with a median $85.5 \%$ of the SCV volume covered by $90 \%$ isodose surface in the traditional plan. (Figure 2) showed the relation between maximum depth of the SCV and the percentage of the SCV encompassed within the $90 \%$ isodose which is significantly decreases for traditional planning versus the conformal plans $(p<0.05)$. Nodes at a depth $>3 \mathrm{~cm}$ would receive $<90 \%$ of the delivered dose in the traditional plan.

The maximum median depth of ICV nodes was $5.8 \mathrm{~cm}$ (range, 3.4-7.2 cm). Ninety seven percent of the ICV volume was covered by the $90 \%$ isodose surface in the conformal plan. This compares with a median of $79.5 \%$ of the ICV volume encompassed by surface in the $90 \%$ isodose the traditional plan. (Figure 3 ) shows the comparison of the ICV depth with the percentage of the ICV volume within the $90 \%$ isodose surface and demonstrates a significant difference between the regression lines for both plans $(p<$ 0.05 ). This means that a decreased radiation dose delivered to the nodes with the traditional plan. Nodes at a depth $\geq$ $4.5 \mathrm{~cm}$ would receive $<90 \%$ of the delivered dose in the traditional plan.

The median depth of BP was $5.4 \mathrm{~cm}$. Seventy nine percent of BP was encompassed within the $90 \%$ isodose surface in the conformal plan versus $40 \%$ for the traditional plan. The median maximum dose to the spinal cord was $34 \mathrm{~Gy}$ in the 3D optimized plan compared with $44 \mathrm{~Gy}$ for the traditional plan. The median dose to the esophagus and apex of lung were $16.5 \mathrm{~Gy}$ and $40 \mathrm{~Gy}$ respectively in the 3D optimized plan compared with $24 \mathrm{~Gy}$ and $34 \mathrm{~Gy}$ for the traditional plan respectively. Most of the esophagus is spared in the optimized plan by angel of the gantry away from the esophagus and cord. The anatomical course of the esophagus is shifted from the right side in the upper level to the left side in the lower level entering the thorax. This means that volume of the esophagus depends on the laterality of breast.

\section{Discussion}

Since a significant benefit in survival has been demonstrated for patients treated with post-operative loco-regional radiotherapy, the interest for optimization by conformal radiotherapy has increased [17-20]. Conformal radiotherapy based on CT delineation of the LNs targets and organ at risk. Based on the RTOG guidelines for regional LNs delineation [15], we found that the field size of optimized technique is more précised than traditional field. This minimizes unnecessary radiation to uninvolved normal tissues in the superior medial and lateral portions [21]. Therefore, delivery of radiation therapy to only those tissues that 
require treatment could potentially result in decreased rates of radiation related shoulder morbidity. It is also possible decreased rates of arm edema. Significant shoulder dysfunction appeared in patients received post mastectomy radiotherapy in the Danish trial [10]. Thus, measures should be taken which could improve long term functional outcome in breast cancer survivor.

Anatomically based guidelines for delineation of the regional LN for loco-regional irradiation of the breast on transverse CT-slices, made in treatment position, have been developed $[\mathbf{1 4}, \mathbf{1 5}]$. These could be used as for conformal radiotherapy. The depth of $L N$ varies according to the body size, weights, subcutaneous adipose tissue, position of the arm $[22,23]$. We found that dose prescription at $3 \mathrm{~cm}$ depth significantly underdoses these regions compared with conformal technique. Unless proper delineation of the LN regions, these regions significantly will receive low doses. We found that SCV nodes $>3 \mathrm{~cm}$ and ICV nodes $>4.5 \mathrm{~cm}$ will not be covered by $90 \%$ isodose surface. However, as the depth to the SCV and ICV nodes increases, the percentage of the SCV volume encompassed within the $90 \%$ isodose surface significantly decreases for cases of therapy planned by using traditional planning versus the conformal optimized plan $[21,23]$.

Estimations of dose received to the brachial plexus for traditional versus optimized planning revealed that higher doses are received to the plexus by using the optimized plans. Although not well documented, clinical studies of peripheral nerve tolerance suggest a $5 \%$ occurrence of radiation-induced brachial plexus injury at doses of $60 \mathrm{~Gy}$ in 2-Gy fractions [24]. This means that despite the delivery of a higher dose of radiation to the brachial plexus volume by using the conformal technique, a higher rate of complications would not be expected with the dose restricted to $50 \mathrm{~Gy}$.

Recent advances in technology have brought significant improvement in radiation therapy. New treatment techniques have been developed to achieve dose distributions that can provide high degrees of target dose conformity and homogeneity. Intensity-modulated radiation therapy (IMRT) implemented clinically as an advanced form of threedimensional conformal radiation therapy (3DCRT). IMRT improved coverage of the target and reduced normal tissue dose while achieving the same tumor coverage. To achieve these goals, a defined clinical target must be determined that allows not only restriction of the treatment field to the designated targets but also allows three-dimensional

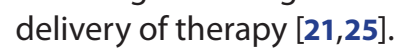

\section{Conclusions}

RTOG has been developed a consensus guidelines for delineation of the breast and its regional LN. The 3D tissue volumes containing the SCV and ICV nodes were defined on CT scans by using readily identifiable anatomic landmarks. Optimized radiation therapy planning provided improved coverage of these structures compared with traditional planning, with greater sparing of uninvolved tissues.

\section{Competing interests}

The authors declare that they have no competing interests.

Publication history

Received: 16-Jan-2013 Revised: 17-Jan-2013

Accepted: 12-Feb-2013 Published: 20-Feb-2013

\section{References}

1. Overgaard M, Nielsen HM and Overgaard J: Is the benefit of postmastectomy irradiation limited to patients with four or more positive nodes, as recommended in international consensus reports? A subgroup analysis of the DBCG 82 b\&c randomized trials. Radiother Oncol 2007, 82:247-53. | Article | Pubmed

2. Overgaard M, Jensen MB, Overgaard J, Hansen PS, Rose $C$, Andersson M, Kamby C, Kjaer M, Gadeberg CC, Rasmussen BB, Blichert-Toft $\mathrm{M}$ and Mouridsen HT: Postoperative radiotherapy in high-risk postmenopausal breast-cancer patients given adjuvant tamoxifen: Danish Breast Cancer Cooperative Group DBCG 82c randomised trial. Lancet 1999, 353:1641-8. I Article I Pubmed

3. Ragaz J, Jackson S M, Le N, Plenderleith I H, Spinelli J J, Basco V E, Wilson K S, Knowling M A, Coppin C M, Paradis M, Coldman A J and Olivotto I A: Adjuvant radiotherapy and chemotherapy in nodepositive premenopausal women with breast cancer. $N$ Engl J Med 1997, 337:956-62. I Article I Pubmed

4. Whelan TJ, Julian J, Wright J, Jadad AR and Levine ML: Does locoregional radiation therapy improve survival in breast cancer? A meta-analysis. J Clin Oncol 2000, 18:1220-9. I Article I Pubmed

5. Halverson K J, Taylor M E, Perez C A, Garcia D M, Myerson R, Philpott G, Levy J, Simpson J R, Tucker G and Rush C: Regional nodal management and patterns of failure following conservative surgery and radiation therapy for stage I and II breast cancer. Int J Radiat Oncol Biol Phys 1993, 26:593-9. I Article I Pubmed

6. Vicini F A, Horwitz E M, Lacerna M D, Brown D M, White J, Dmuchowski C F, Kini V R and Martinez A: The role of regional nodal irradiation in the management of patients with early-stage breast cancer treated with breast-conserving therapy. Int J Radiat Oncol Biol Phys 1997, 39:1069-76. | Article | Pubmed

7. Dahl-Iversen $\mathrm{E}$ : [Research on the microscopic metastases of breast cancers into the para-sternal and subclavicular lymph nodes]. Mem Acad Chir (Paris) 1952, 78:651-2. I Article I Pubmed

8. Smith J A, 3rd, Gamez-Araujo J J, Gallager H S, White E C and McBride C M: Carcinoma of the breast: analysis of total lymph node involvement versus level of metastasis. Cancer 1977, 39:527-32. | Article I Pubmed

9. Halverson K J, Taylor M E, Perez C A, Garcia D M, Myerson R, Philpott G, Levy J, Simpson J R, Tucker G and Rush C: Regional nodal management and patterns of failure following conservative surgery and radiation therapy for stage I and II breast cancer. Int J Radiat Oncol Biol Phys 1993, 26:593-9. I Article I Pubmed

10. Hojris I, Andersen J, Overgaard M and Overgaard J: Late treatmentrelated morbidity in breast cancer patients randomized to postmastectomy radiotherapy and systemic treatment versus systemic treatment alone. Acta Oncol 2000, 39:355-72. | Article | Pubmed

11. Bentel GC, Marks LB, Hardenbergh PH and Prosnitz LR: Variability of the depth of supraclavicular and axillary lymph nodes in patients with breast cancer: is a posterior axillary boost field necessary? Int J Radiat Oncol Biol Phys 2000, 47:755-8. I Article I Pubmed

12. Klages H T, Szafinski F and Makoski H B: Variation in "supraclavicular" lymph node depth is partly determined by treatment position. Strahlenther Onkol 2000, 176:315-8. I Article I Pubmed

13. Madu C N, Quint D J, Normolle D P, Marsh R B, Wang E Y and Pierce $L J$ : Definition of the supraclavicular and infraclavicular nodes: implications for three-dimensional CT-based conformal radiation 
therapy. Radiology 2001, 221:333-9. | Article | Pubmed

14. Dijkema I M, Hofman P, Raaijmakers C P, Lagendijk J J, Battermann J $J$ and Hillen B: Loco-regional conformal radiotherapy of the breast: delineation of the regional lymph node clinical target volumes in treatment position. Radiother Oncol 2004, 71:287-95. | Article | Pubmed

15. Breast Cancer Atlas for Radiation Therapy Planning: Consensus Definitions. I Website

16. Gebarski KS, Glazer GM and Gebarski SS: Brachial plexus: anatomic, radiologic, and pathologic correlation using computed tomography. $J$ Comput Assist Tomogr 1982, 6:1058-63. | Article | Pubmed

17. Muren LP, Maurstad G, Hafslund R, Anker G and Dahl O: Cardiac and pulmonary doses and complication probabilities in standard and conformal tangential irradiation in conservative management of breast cancer. Radiother Oncol 2002, 62:173-83. | Article | Pubmed

18. Hong L, Hunt M, Chui C, Spirou S, Forster K, Lee H, Yahalom J, Kutcher GJ and McCormick B: Intensity-modulated tangential beam irradiation of the intact breast. Int J Radiat Oncol Biol Phys 1999, 44:1155-64. | Article | Pubmed

19. Landau D, Adams EJ, Webb S and Ross G: Cardiac avoidance in breast radiotherapy: a comparison of simple shielding techniques with intensity-modulated radiotherapy. Radiother Oncol 2001, 60:247-55. | Article | Pubmed

20. Takeda A, Shigematsu N, Ikeda T, Kawaguchi O, Kutsuki S, Ishibashi $\mathrm{R}$, Kunieda E, Takeda T, Takemasa $\mathrm{K}$, Ito $\mathrm{H}$, Uno T, Jinno $\mathrm{H}$ and Kubo A: Evaluation of novel modified tangential irradiation technique for breast cancer patients using dose-volume histograms. Int J Radiat Oncol Biol Phys 2004, 58:1280-8. | Article | Pubmed

21. Madu CN, Quint DJ, Normolle DP, Marsh RB, Wang EY and Pierce LJ: Definition of the supraclavicular and infraclavicular nodes: implications for three-dimensional CT-based conformal radiation therapy. Radiology 2001, 221:333-9. | Article | Pubmed

22. Mansur DB, Kong FM, El Naqa I, Taylor ME, Zoberi I, Bradley JD, Perez $\mathrm{CA}$ and Klein EE: CT localization of axillary lymph nodes in relation to the humeral head: significance of arm position for radiation therapy planning. Radiother Oncol 2005, 77:191-3. | Article | Pubmed

23. Bentel GC, Marks LB, Hardenbergh PH and Prosnitz LR: Variability of the depth of supraclavicular and axillary lymph nodes in patients with breast cancer: is a posterior axillary boost field necessary? Int J Radiat Oncol Biol Phys 2000, 47:755-8. | Article | Pubmed

24. Emami B, Lyman J, Brown A, Coia L, Goitein M, Munzenrider JE, Shank $B$, Solin $L$ and Wesson M: Tolerance of normal tissue to therapeutic irradiation. Int J Radiat Oncol Biol Phys 1991, 21:109-22. | Article | Pubmed

25. Ma CM, Ding M, Li JS, Lee MC, Pawlicki T and Deng J: A comparative dosimetric study on tangential photon beams, intensity-modulated radiation therapy (IMRT) and modulated electron radiotherapy (MERT) for breast cancer treatment. Phys Med Biol 2003, 48:909-24. | Article | Pubmed

\section{Citation:}

Aboziada MA, Hashem MA and Ahmed AS:

Three dimentional CT-based evaluation of the supraclavicular and infraclavicular nodes and calculation of the administrated dose. journal of Cancer Therapeutics and Research 2013, 2:11. http://dx.doi.org/10.7243/2049-7962-2-11 